\title{
Retraction Note: EOL automatic detection scheme for new energy vehicle battery system manufacturing process
}

\author{
Yisong Chen ${ }^{1} \cdot$ Haibo $\mathrm{Xu}^{1} \cdot$ Shuru Liu ${ }^{1}$
}

Published online: 22 November 2021

(c) Saudi Society for Geosciences 2021

Retraction Note: Arabian Journal of Geosciences (2021) 14: 903 https://doi.org/10.1007/s12517-021-07248-3

The Editor-in-Chief and the Publisher have retracted this article because the content of this article is nonsensical. The peer review process was not carried out in accordance with the Publisher's peer review policy. The authors have not responded to correspondence regarding this retraction.

The original article can be found online at https://doi.org/10.1007/ s12517-021-07248-3.

Yisong Chen

caqccys@163.com

1 School of Automobile, Chang' an University, Xi' an 710064,

Shaanxi, China 